\title{
THE PROCESS INCAPABILITY INDEX UNDER FUZZINESS WITH AN APPLICATION FOR DECISION MAKING
}

\author{
İhsan Kaya \\ Ylldız Technical University, Department of Industrial Engineering, 34349 Yılduz Istanbul \\ E-mail:ihkaya@yildiz.edu.tr;iekaya@yahoo.com
}

Received 22 August 2012

Accepted 3 March 2013

\begin{abstract}
Process capability indices (PCIs) provide numerical measures on whether a process confirms to the defined capability prerequisite. They have been used to measure the ability of process to decide how well the process meets the specification limits (SLs). The PCIs have been successfully applied by companies for evaluating the quality and productivity performance. In this paper, one of the most important PCIs, process incapability index $\left(C_{p p}\right)$ that provides more process information than other PCIs is analyzed together with the indices inaccuracy $\left(C_{i a}\right)$ and imprecision $\left(C_{i p}\right)$ under uncertainty. When there are some uncertainties in process parameters, traditional PCIs have failed to summarize process performance. Therefore the fuzzy set theory (FST) can be employed to overcome this problem. In this paper, the index $C_{p p}$ is analyzed by using the FST to obtain more sensitiveness and a deep and flexible analysis. The fuzzy estimations of the index $C_{p p}$ are derived for both of triangular and trapezoidal fuzzy numbers. The obtained fuzzy incapability index $\left(\tilde{C}_{p p}\right)$ is applied in a decision making process to determine the most appropriate supplier among alternatives for a construction firm in Turkey.
\end{abstract}

Keywords: Process incapability index, inaccuracy index, imprecision index, fuzzy set theory, decision making

\section{Introduction}

Understanding the structure of a process and quantifying process performance no doubt are essential for successful quality improvement initiatives. Process capability analysis has become an important and well-defined tool in applications of statistical process control (SPC) to a continuous improvement of quality and productivity. The relationship between the actual process performance and the specification limits (or tolerance) may be quantified using suitable process capability indices. Process capability indices (PCIs), in particular $C_{p}, C_{a}, C_{p k}, C_{p m}$, and $C_{p m k}$, which provide numerical measures of whether or not a manufacturing process is capable to meet a predetermined level of production tolerance, have received substantial attention in research activities as well as an increased usage in process assessments and purchasing decisions during last two decades. The first process capability index 
appearing in the engineering literature was presumably the simple "precision" index $C_{p}$. This index considers the overall process variability relative to the manufacturing tolerance as a measure of process precision (or product consistency) (Kane, 1986; Kotz and Johnson, 1993; Wu et al., 2009):

$C_{p}=\frac{U S L-L S L}{6 \sigma}$

where $\sigma$ is the process standard deviation, USL and $L S L$ are the upper and the lower specification limits (SLs), respectively.

Since the index $C_{p}$ cannot provide an assessment of process centering (targeting), the index $C_{p k}$ was considered. The standard definition is of the index $C_{p k}$ as follows ((Kane, 1986; Kotz and Johnson, 1993; Wu et al., 2009)):

$C_{p k}=\min \left\{\frac{U S L-\mu}{3 \sigma}, \frac{\mu-L S L}{3 \sigma}\right\}$

The index $C_{p k}$ was developed because $C_{p}$ does not adequately deal with cases where process mean $\mu$ is not centered (the mean does not equal to the midpoint $m$ ). However, $C_{p k}$ by itself still cannot provide an adequate measure of process centering. That is, a large value of $C_{p k}$ does not provide information about the location of the mean in the tolerance interval $(U S L-L S L)$. The $C_{p}$ and $C_{p k}$ indices are appropriate measures of progress for quality improvement situations when reduction of variability is the guiding factor and process yield is the primary measure of a success. However, they are not related to the cost of failing to meet customers' requirement of the target. A well-known pioneer in the quality control, G. Taguchi, on the other hand, pays special attention on the loss in product's worth when one of product's characteristics deviates from the customers' ideal value $T$ (target value). To take this factor into account, the index $C_{p m}$ was introduced. The index is geared towards measuring the ability of a process to cluster around the target, and reflects the degrees of process targeting (centering). The index $C_{p m}$ incorporates the variation of production items relative to the $\mathrm{T}$ and the SLs. The index $C_{p m}$ is defined as follows ((Kane, 1986; Kotz and Johnson, 1993; Wu et al., 2009)):

$C_{p m}=\frac{U S L-L S L}{6 \sqrt{\sigma^{2}+(\mu-T)^{2}}}$
PCIs fitting for nominal-the-best type quality characteristics are effective tools to assess process capability since these indices can reflect a centering process capability and process yield adequately. The index $C_{p p}$ provides additional and individual information concerning the process accuracy and the process precision. It has been widely used to provide numerical measures on whether a production is capable of producing items within the SLs preset by the designer (Chen and Chen, 2008).

In this paper, this index is analyzed under fuzziness. Zadeh (1965) introduced the fuzzy set theory (FST) that is a branch of mathematics that allows a computer to model the real world in the same way that people do to overcome some uncertain and vague concepts in variables. The FST has a wide application in many fields such as industrial and production management (see Kahraman et al., 2006) since it provides a simple way to reason with vague, ambiguous, and imprecise input or knowledge. The FST has also been applied in process capability analysis to provide more information and more sensitiveness on PCIs. The FST brings an advantage to easily define main characteristics of PCIs by using linguistic variables. Although PCIs have been analyzed under fuzziness, the literature has no research about fuzzy estimation of process incapability index $\left(\tilde{C}_{p p}\right)$. So this paper investigates the index $\tilde{C}_{p p}$ by obtaining fuzzy estimations of inaccuracy index $\left(\tilde{C}_{i a}\right)$ and imprecision index $\left(\tilde{C}_{i p}\right)$. The fuzzy estimations of the index $\tilde{C}_{p p}$ are produced for both of triangular fuzzy numbers (TFN) and trapezoidal fuzzy numbers (TrFNs) by using fuzzy specification limits $(S \tilde{L} s)$, fuzzy mean $(\tilde{\mu})$, fuzzy variance $\left(\tilde{\sigma}^{2}\right)$ and fuzzy target value $(\tilde{T})$. The proposed fuzzy indices are used in a decision making process to determine the most appropriate supplier for a construction firm that is a multi-criteria decision making problem. However, only quality is considered for this problem by taking into account the index $\tilde{C}_{p p}$. Since we have an assumption that the suppliers are equivalent in terms of other criteria other than quality (i.e. price, delivery performance etc.).

The rest of this paper is organized as follows: The process incapability index is briefly introduced in Section 2. The fuzzy estimations of process mean and variance are obtained and the $\alpha$-cuts of fuzzy estimations with fuzzy data for $\tilde{C}_{i a}, \tilde{C}_{i p}$ and $\tilde{C}_{p p}$ are produced in Section 3. Section 4 includes a real 
case application to a supplier selection problem by using the index $\tilde{C}_{p p}$. The conclusions and future research directions are discussed in Section 5.

\section{Process Incapability Index}

Greenwich and Jahr-Schaffrath (1995) defined the index $C_{p p}$ which provides an uncontaminated separation between information concerning process accuracy and process precision as follow:

$C_{p p}=C_{i a}+C_{i p}$

where the inaccuracy index $C_{i a}=\left(\frac{\mu-T}{D}\right)^{2}$ and imprecision index $C_{i p}=\left(\frac{\sigma}{D}\right)^{2}$. Thus,

$C_{p p}=\left(\frac{\mu-T}{D}\right)^{2}+\left(\frac{\sigma}{D}\right)^{2}$

where

$D=\frac{\min \{T-L S L, U S L-T\}}{3}=\frac{d^{*}}{3}$

The index $C_{p p}$ can be widely used to summarize process performance since it simultaneously detects process inaccuracy and process imprecision by using both of the indices $C_{i a}$ and $C_{i p}$.

The index $C_{p p}$ contains the information namely, inaccuracy (the departure of the process mean, $\mu$, from the target value, $T$ ) and imprecision (the magnitude of the process variation, $\sigma^{2}$ ). Moreover, the index $C_{p p}$ provides an uncontaminated separation between information concerning the process accuracy and precision. Often, PCIs are employed to assess process capability because the process accuracy is of significance. Therefore, this information separation is highly beneficial because it indicates to what degree the process inaccuracy contributes to the process being incapable of meeting the specifications. The index $C_{p p}$ assumes a smaller value for a process more capable of meeting its specifications and a larger value for a less capable process. A process is most capable when $C_{p p}=0$. For this, the process mean must be at the process target $(\mu=\mathrm{T})$ and the process variance must be zero $\left(\sigma^{2}=0\right)$. Any non-zero value of $C_{p p}$ indicates some degree of incapability of the process. Thus, $C_{p p}$ is a process incapability index (Greenwich and Jahr-Schaffrath, 1995). Table 1 presents the quality conditions and the corresponding $C_{p p}$ values (Chen and Chen, 2008).

Table 1 Classification of quality conditions

\begin{tabular}{lc}
\hline Quality Condition & \multicolumn{1}{c}{$C_{p p}$} \\
\hline Inadequate & $C_{p p}>1.00$ \\
Capable & $0.56<C_{p p} \leq 1.00$ \\
Satisfactory & $0.44<C_{p p} \leq 0.56$ \\
Excellent & $0.25<C_{p p} \leq 0.44$ \\
Super & $C_{p p} \leq 0.25$
\end{tabular}

The index $C_{p p}$ has been widely analyzed to provide numerical measures on whether a production is capable in the literature. Chen (1998a) proposed the uniformly minimum variance unbiased estimator and the probability density function of the index $C_{p p}$. Pearn et al. (2002) developed a statistical hypothesis testing method based on the index $C_{p p}$ to determine whether a given process meets quality requirements or not. Huang et al. (2002) showed the relationship between process incapability index $C_{p p}$ and process yield. Chen et al. (2005) determined the score index $\left(R_{i}\right)$ and then applied it to assess the process performance of contract manufacturer by using the index $C_{p p}$. Chou et al. (2006) analyzed the results of a simulation study on the behavior of four $95 \%$ bootstrap confidence intervals which are standard bootstrap, percentile bootstrap, biased-corrected percentile bootstrap, and biasedcorrected and accelerated bootstrap for estimating the index $C_{p p}$ when data were from a specific Burr distribution. Ke et al. (2009) obtained the interval estimations of incapability index $C_{p p}$ for non-normal processes. Unlike the existing studies, in this paper, the fuzzy estimations of index $\tilde{C}_{p p}$ are produced by obtaining fuzzy estimations of the indices $\tilde{C}_{i a}$ and $\tilde{C}_{i p}$ and they are suggested for a decision making process. 


\section{Fuzzy Process Incapability Index}

The fuzzy logic is a matter of the FST particularly used to dealing with imprecise information by using membership function and was formalized by Zadeh (1965). In a classical set, an element belongs to, or does not belong to, a set whereas an element of a fuzzy set naturally belongs to the set with a membership value from the interval $[0,1]$. The FST has been studied extensively over the past 30 years since it gives an advantage to define the parameters more flexible and to analyze the results with more sensitiveness. Although most of the early interest in the FST was representing of uncertainty in human cognitive processes, it is now applied to problems in engineering, business, health sciences, economic, and the natural sciences. Over the last years there have been successful applications of the FST in quality management and assurance. After the inception of fuzzy sets in statistical process control, some studies have been made to combine PCIs and the FST such as $C_{p}$ (Yongting, 1996; Lee et al., 1999; Chen et al., 2003a; Tsai and Chen, 2006; Parchami et al., 2005; 2006; Parchami and Mashinchi, 2007; Kaya and Kahraman, 2008; 2009b; 2010c; 2011; 2011b; Kahraman and Kaya, 2009; Parchami and Mashinchi, 2010), $C_{a}$ (Kahraman and Kaya, 2009b; Kaya and Kahraman 2010; 2011; 2011a), $C_{p k}$ (Lee, 2001; Parchami et al., 2005; 2006; Parchami and Mashinchi, 2007; Kaya and Kahraman, 2008; 2009b; 2010c; 2011; 2011b; Kahraman and Kaya, 2009; Parchami and Mashinchi, 2010), $C_{p m}$ (Chen et al., 2003b; Parchami et al., 2005; 2006; Parchami and Mashinchi, 2007; Hsu and Shu, 2008; Ramezani et al., 2009; Kaya and Kahraman, 2011; Chen et al., 2010; Parchami and Mashinchi, 2010), $C_{p m k}$ (Parchami et al., 2005; Abdolshah et al., 2010; Kaya and Kahraman, 2011; Parchami and Mashinchi, 2010), incapability indices (Kahraman and Kaya, 2011; Kaya and Baraçl1, 20012) and fuzzy PCIs with asymmetric tolerances (Kaya and Baraçl1, 20012; Kaya and Kahraman, 20010e). In this paper, unlike the previous studies, fuzzy estimations of the index $\tilde{C}_{p p}, \tilde{C}_{i a}$ and $\tilde{C}_{i p}$ are derived for the first time by using $\tilde{\mu}, \tilde{\sigma}^{2}$ together with $S \tilde{L} s$ and $\tilde{T}$ values.

In the first stage we need to obtain fuzzy estimations of $\tilde{\mu}$ and $\tilde{\sigma}^{2}$. For this aim, we have to estimate $\mu$ and $\sigma^{2}$ from the sample. Then the membership functions of these parameters are obtained by using these point estimators. In this paper, the Buckley's fuzzy estimation method (Buckley and Eslami, 2004; Buckley 2004; 2005;
2006) is used to obtain the membership functions of the $\tilde{\mu}$ and $\tilde{\sigma}^{2}$ as detailed below.

\subsection{Fuzzy Process Mean}

Let $x$ be a random variable which has a probability density function, $N\left(\mu, \sigma^{2}\right)$, with unknown mean $(\mu)$ and known variance $\left(\sigma^{2}\right)$. A random sample $x_{1}, x_{2}, \ldots, x_{n}$ from $N\left(\mu, \sigma^{2}\right)$ can be taken to estimate $\mu$. The mean of this sample is a crisp number $(\bar{x})$. Because of the central limit theorem, $\bar{x}$ has a normal probability density function, $N\left(\mu, \frac{\sigma^{2}}{n}\right)$, and $\frac{\bar{x}-\mu}{\sigma / \sqrt{n}}$ has standard normal probability density function $N(0,1)$. Therefore we can write (Buckley and Eslami, 2004; Buckley 2004; 2005; 2006):

$$
\begin{aligned}
& P\left(-z_{\beta / 2} \leq \frac{\bar{x}-\mu}{\frac{\sigma}{\sqrt{n}}} \leq z_{\beta / 2}\right)=1-\beta \\
& P\left(\bar{x}-z_{\beta / 2} \frac{\sigma}{\sqrt{n}} \leq \mu \leq \bar{x}+z_{\beta / 2} \frac{\sigma}{\sqrt{n}}\right)=1-\beta
\end{aligned}
$$

where $z_{\beta / 2}$ is the $z$ value of the probability of a $N(0,1)$ random variable exceeding $\beta / 2$. As a result, the $(1-\beta) 100 \%$ confidence interval for $\mu$ can be obtained by using Eq. (9):

$$
\left[\theta_{1}(\beta), \theta_{2}(\beta)\right]=\left\lfloor\bar{x}-z_{\beta / 2} \frac{\sigma}{\sqrt{n}}, \bar{x}+z_{\beta / 2} \frac{\sigma}{\sqrt{n}}\right\rfloor \text { (9) }
$$

where $z_{\beta / 2}$ is defined as follows:

$$
\int_{-\infty}^{z_{\beta} / 2} N(0,1) d x=1-\frac{\beta}{2}
$$

If $\beta$ values are taken into account as $\alpha$-cuts, the fuzzy estimator of $\mu, \tilde{\mu}$, can be obtained by using Eq. (11):

$$
\left[\mu_{l}(\alpha), \mu_{r}(\alpha)\right]_{z}=\left\lfloor\bar{x}-z_{\alpha / 2} \frac{\sigma}{\sqrt{n}}, \bar{x}+z_{\alpha / 2} \frac{\sigma}{\sqrt{n}}\right\rfloor
$$

\subsection{Fuzzy Process Variance}

Let $x$ be a random variable which has a probability density function, $N\left(\mu, \sigma^{2}\right)$, with unknown mean $(\mu)$ and unknown variance $\left(\sigma^{2}\right)$. A random 
sample $x_{1}, x_{2}, \ldots, x_{n}$ from $N\left(\mu, \sigma^{2}\right)$ can be taken to estimate $\sigma^{2}$. Also it is known that $\frac{(n-1) s^{2}}{\sigma^{2}}$ has a "chi-square distribution" with $n-1$ degrees of freedom. Therefore the fuzzy estimator for $\sigma^{2}$ can be defined by the following confidence interval (Buckley and Eslami, 2004; Buckley 2004; 2005; 2006):

$$
\left(\frac{(n-1) s^{2}}{\chi_{R, \beta / 2}^{2}} \leq \sigma^{2} \leq \frac{(n-1) s^{2}}{\chi_{L, \beta / 2}^{2}}\right)
$$

where $\chi_{R, \beta / 2}^{2}$ and $\chi_{L, \beta / 2}^{2}$ are the points on the right and left sides of the $\chi^{2}$ density function, respectively. This formula is a biased estimate for $\sigma^{2}$. Buckley defined the following equations to obtain an unbiased fuzzy estimator $(0.01 \leq \beta \leq 1.00) \quad$ (Buckley and Eslami, 2004; Buckley 2004; 2005; 2006):

$$
R(\lambda)=[1-\lambda] \chi_{L, 0.005}^{2}+\lambda(n-1)
$$

Then the unbiased $(1-\beta) 100 \%$ confidence interval for $\sigma^{2}$ should be calculated from Eq. (14):

$$
\hat{\sigma}^{2}=\left\lfloor\frac{(n-1) s^{2}}{L(\lambda)}, \frac{(n-1) s^{2}}{R(\lambda)}\right\rfloor,
$$$$
\text { where } 0 \leq \lambda \leq 1 \text {. }
$$

If $\beta$ is taken into account as an $\alpha$-cut level, the fuzzy triangular membership function for $\sigma^{2}$ is obtained from Eq. (14) as given in Eq. (15). The triangular fuzzy membership functions can be built by placing these confidence intervals one on top of another.

$$
\tilde{\sigma}^{2}(\alpha)=\left\lfloor\frac{(n-1) s^{2}}{[1-\alpha] \chi_{R, 0.005}^{2}+(n-1) \alpha}, \frac{(n-1) s^{2}}{[1-\alpha] \chi_{L, 0.005}^{2}+(n-1) \alpha}\right\rfloor, \quad 0.01 \leq \alpha \leq 1.00
$$

After the fuzzy estimation of $\sigma^{2}$ is obtained, it is now necessary that to reconsider the fuzzy estimation of $\mu$. Eq. (11) can be reevaluated by taking into account $\tilde{\sigma}^{2}$ as follows:

$\mu_{\tilde{\sigma}}(\alpha)=\left\lfloor\mu_{l, \tilde{\sigma}}(\alpha), \mu_{r, \tilde{\sigma}}(\alpha)\right\rfloor$

where $\mu_{l}(\alpha)$ and $\mu_{r}(\alpha)$ represent the two sides of the fuzzy estimation of $\mu$ and can be calculated by using Eqs. (17-18).

$$
\begin{array}{ll}
\mu_{l, \tilde{\sigma}}(\alpha)=\min \left(\bar{x}-z_{\alpha / 2} \frac{\sigma_{i}(\alpha)}{\sqrt{n}}\right) & i=1,2 \\
\mu_{r, \tilde{\sigma}}(\alpha)=\max \left(\bar{x}+z_{\alpha / 2} \frac{\sigma_{i}(\alpha)}{\sqrt{n}}\right) & i=1,2
\end{array}
$$

where $\sigma_{1}(\alpha)$ and $\sigma_{2}(\alpha)$ represent the left and right sides of $\tilde{\sigma}^{2}$, respectively and can be calculated by using Eq. (15).

\subsection{Specification Limits and Target Value under Fuzziness}

In this subsection, two main parameters of process capability analysis $S L s$ and $T$, are considered as fuzzy numbers to obtain fuzzy estimations of the index $\tilde{C}_{p p}, \tilde{C}_{i a}$ and $\tilde{C}_{i p}$. For this aim, SLs and $T$ are analyzed based on the FST by defining them as TFN and TrFN.

It is possible to define the SLs and $\mathrm{T}$ by using a linguistic variable such as "approximately". TFN are suitable to convert this variable to fuzzy numbers. By the way, in some cases, SLs and $\mathrm{T}$ can be defined by an expression like "between $X$ and $Y$ " where $\operatorname{TrFN}$ are more suitable to convert them to fuzzy numbers. So TFN and TrFN are used in this paper.

Suppose we have a fuzzy process for which the T, upper and lower SLs are defined as $\tilde{\mathrm{T}}=\operatorname{TFN}\left(t_{1}, t_{2}, t_{3}\right), \quad U \tilde{S} L=\operatorname{TFN}\left(u_{1}, u_{2}, u_{3}\right)$, and $L \tilde{S} L=\operatorname{TFN}\left(l_{1}, l_{2}, l_{3}\right)$, respectively by using TFN. The $\alpha$-cuts of them are obtained as in Eq. (19): 


$$
\begin{aligned}
& U \tilde{S} L(\alpha)=\left[\left(u_{2}-u_{1}\right) \alpha+u_{1},\left(u_{2}-u_{3}\right) \alpha+u_{3}\right] \\
& L \tilde{S} L(\alpha)=\left[\left(l_{2}-l_{1}\right) \alpha+l_{1},\left(l_{2}-l_{3}\right) \alpha+l_{3}\right] \\
& \tilde{T}(\alpha)=\left[\left(t_{2}-t_{1}\right) \alpha+t_{1},\left(t_{2}-t_{3}\right) \alpha+t_{3}\right]
\end{aligned}
$$

$S L s$ and $T$ can also be represented by using TrFN. Assume that $\tilde{T}, U \tilde{S} L$ and $L \tilde{S} L$ are defined as $\tilde{\mathrm{T}}=\operatorname{TrFN}\left(t_{1}, t_{2}, t_{3}, t_{4}\right), \quad U \tilde{S} L=\operatorname{TrFN}\left(u_{1}, u_{2}, u_{3}, u_{4}\right)$ and $L \tilde{S} L=\operatorname{TrFN}\left(l_{1}, l_{2}, l_{3}, l_{4}\right)$, respectively. The $\alpha$-cuts are as in Eq. (20):

$$
\begin{aligned}
& U \tilde{S} L(\alpha)=\left[\left(u_{2}-u_{1}\right) \alpha+u_{1},\left(u_{3}-u_{4}\right) \alpha+u_{4}\right] \\
& L \tilde{S} L(\alpha)=\left[\left(l_{2}-l_{1}\right) \alpha+l_{1},\left(l_{3}-l_{4}\right) \alpha+l_{4}\right] \\
& \tilde{T}(\alpha)=\left[\left(t_{2}-t_{1}\right) \alpha+t_{1},\left(t_{3}-t_{4}\right) \alpha+t_{4}\right]
\end{aligned}
$$

\subsection{Fuzzy estimation of the process incapability} index $\left(\tilde{C}_{p p}\right)$

In this paper the fuzzy estimations of index $\tilde{C}_{p p}$ is derived by using the fuzzy estimations of index $\tilde{C}_{i a}$

$$
\begin{aligned}
& \tilde{C}_{i a}(\alpha)=\left\{C_{i a}^{L}(\alpha), C_{i a}^{R}(\alpha)\right\}=\left\{\left(\frac{\mu_{l, \tilde{\sigma}}(\alpha)-\tilde{T}_{r}(\alpha)}{\tilde{D}_{r}(\alpha)}\right)^{2},\left(\frac{\mu_{r, \tilde{\sigma}}(\alpha)-\tilde{T}_{l}(\alpha)}{\tilde{D}_{l}(\alpha)}\right)^{2}\right\} \\
& \tilde{C}_{i p}(\alpha)=\left\{C_{i p}^{L}(\alpha), C_{i p}^{R}(\alpha)\right\}=\left\{\frac{\tilde{\sigma}_{l}^{2}(\alpha)}{\tilde{D}_{r}^{2}(\alpha)}, \frac{\tilde{\sigma}_{r}^{2}(\alpha)}{\tilde{D}_{l}^{2}(\alpha)}\right\}
\end{aligned}
$$

The left $\left(\tilde{C}_{i a}^{L}(\alpha)\right)$ and right $\left(\tilde{C}_{i a}^{R}(\alpha)\right)$ sides of the membership function for $\tilde{C}_{i a}$ can be obtained with respect to either TFN or TrFN by using Eqs. (24) and (25):

$$
\tilde{C}_{i a}^{L}(\alpha)= \begin{cases}\left(\frac{\min \left(\bar{x}-z_{\alpha / 2} \frac{\sigma_{i}(\alpha)}{\sqrt{n}}\right)-\left(t_{2}-t_{3}\right) \alpha-t_{3}}{\left.\frac{\min \left\{\left(u_{2}-u_{3}-t_{2}+t_{1}\right) \alpha+u_{3}-t_{1},\left(t_{2}-t_{3}-l_{2}+l_{1}\right) \alpha+t_{3}-l_{1}\right\}}{3}\right)^{2},}\right. & \text { for TFNs } \\ \left(\frac{\min \left(\bar{x}-z_{\alpha / 2} \frac{\sigma_{i}(\alpha)}{\sqrt{n}}\right)-\left(t_{3}-t_{4}\right) \alpha-t_{4}}{\left.\frac{\min \left\{\left(u_{3}-u_{4}-t_{2}+t_{1}\right) \alpha+u_{4}-t_{1},\left(t_{3}-t_{4}-l_{2}+l_{1}\right) \alpha+t_{4}-l_{1}\right\}}{3}\right)^{2}}\right)^{2}, & \text { for TrFNs }\end{cases}
$$




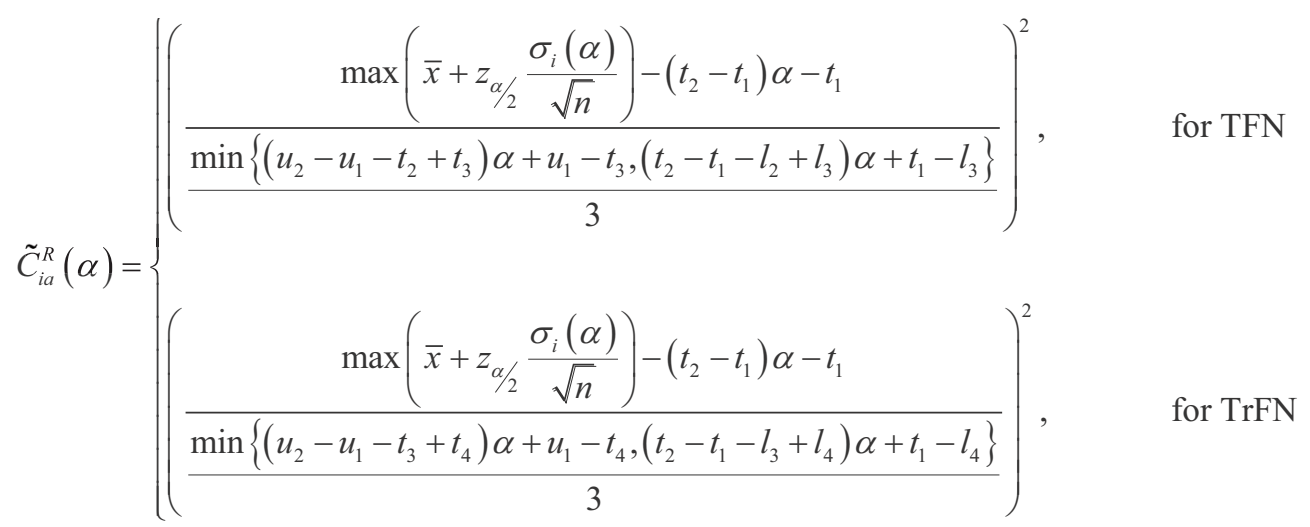

The left $\left(\tilde{C}_{i p}^{L}(\alpha)\right)$ and right $\left(\tilde{C}_{i p}^{R}(\alpha)\right)$ sides of the membership function for $\tilde{C}_{i p}$ can also be drawn with respect to either TFN or TrFN by using Eqs. (26) and (27):

$$
\tilde{C}_{i p}^{L}(\alpha)=\left\{\begin{array}{l}
\left(\frac{\frac{(n-1) s^{2}}{(1-\alpha) \chi_{R, 0.005}^{2}+(n-1) \alpha}}{\left.\frac{\min \left\{\left(u_{2}-u_{3}-t_{2}+t_{1}\right) \alpha+u_{3}-t_{1},\left(t_{2}-t_{3}-l_{2}+l_{1}\right) \alpha+t_{3}-l_{1}\right\}}{3}\right)^{2}}\right), \\
\left(\begin{array}{l}
\frac{(n-1) s^{2}}{(1-\alpha) \chi_{R, 0.005}^{2}+(n-1) \alpha} \\
\left.\frac{\min \left\{\left(u_{3}-u_{4}-t_{2}+t_{1}\right) \alpha+u_{4}-t_{1},\left(t_{3}-t_{4}-l_{2}+l_{1}\right) \alpha+t_{4}-l_{1}\right\}}{3}\right)^{2}
\end{array}\right),
\end{array}\right.
$$

$$
\tilde{C}_{i p}^{R}(\alpha)= \begin{cases}\left(\frac{\frac{(n-1) s^{2}}{(1-\alpha) \chi_{L, 0.005}^{2}+(n-1) \alpha}}{\left.\frac{\min \left\{\left(u_{2}-u_{1}-t_{2}+t_{3}\right) \alpha+u_{1}-t_{3},\left(t_{2}-t_{1}-l_{2}+l_{3}\right) \alpha+t_{1}-l_{3}\right\}}{3}\right)^{2}}\right), & \text { for TFN } \\
\left(\begin{array}{ll}
\frac{(n-1) s^{2}}{(1-\alpha) \chi_{L, 0.05}^{2}+(n-1) \alpha} \\
\left(\frac{\min \left\{\left(u_{2}-u_{1}-t_{3}+t_{4}\right) \alpha+u_{1}-t_{4},\left(t_{2}-t_{1}-l_{3}+l_{4}\right) \alpha+t_{1}-l_{4}\right\}}{3}\right)^{2}
\end{array}\right), & \text { for TrFN }\end{cases}
$$

As seen from above equations, it is a necessity to compare fuzzy values for determining the minimum value. It is possible to meet many ranking methods in the literature. In this paper a defuzzication method named the total integral value method with 
an index of optimism $\omega \in[0,1]$ and proposed by Liou and Wang (1992) is used. Let $\tilde{A}$ be a fuzzy number with left membership function $f_{\tilde{A}}^{L}$ and right membership function $f_{\tilde{A}}^{R}$. Then the total integral value is defined as (Kahraman et al., 2004):

$E_{\omega}(\tilde{A})=\omega E_{R}(\tilde{A})+(1-\omega) E_{L}(\tilde{A})$

where

$E_{R}(\tilde{A})=\int_{\alpha}^{\beta} x f_{\tilde{A}}^{R}(x) d x$

and

$$
E_{L}(\tilde{A})=\int_{\gamma}^{\delta} x f_{\tilde{A}}^{L}(x) d x
$$

where $-\infty<\alpha \leq \beta \leq \gamma \leq \delta<\infty$. For a triangular fuzzy number, $\tilde{A}=(a, b, c)$, the total integral value is obtained by

$$
E_{\omega}(\tilde{A})=\frac{1}{2}[\omega(a+b)+(1-\omega)(b+c)] .
$$

\section{A Real Case Application}

In this paper, the proposed index $\tilde{C}_{p p}$ is used to determine the most appropriate supplier among alternatives for a construction firm in Turkey. A firm named Beton Construction will select a supplier.

Beton Construction, one of the leading companies in the Turkish construction industry, was established in 1963. During its initial years, Beton Construction specialized particularly in piers, quays and ports and thus participated in the construction of one third of Turkish ports. Beton Construction played an active role in the development of Turkey's infrastructure through numerous contracts covering transportation, energy, environmental and industrial projects. Demonstrating the same level of performance in significant super structure projects in Turkey, the firm expanded its operations into international construction industry in 1983. Beton Construction and its subsidiaries, providing services in a wide range of areas (such as tourism, finance, information technology, manufacturing and investment), were organized under the umbrella of ABC Holding Company in 1997. Beton Construction, the flagship entity of the group, with its experienced and knowledgeable work force, always aiming at offering services matching global standards, has ISO 9001 Quality Reassurance System Certificates and OHSAS 18001 Occupational Health and Safety Management Certificates to document its commitment to quality. Beton Construction has recently undertaken some land development projects such as "Metrocity Millennium", a residential, commercial and shopping center complex in İstanbul, and a Business Center in Söğütözü, Ankara. Beton Construction was also involved in the building of drinking and wastewater treatment plants, water and sewage lines and underground transport systems in various cities in Turkey. As the civil contractor of international consortiums, the Company completed Ankaray LRTS and ASKI - Ankara Waste Water Treatment Plant, the largest of its kind in Europe. Adana Wastewater Treatment Plant, İstanbul Metro, Ünye - Piraziz, Bolaman - Perşembe Highways, Şanlıurfa - Suruç and Ankara - Pozantı Motorways, Kadıköy - Kartal Rail Mass Transit System are a few of the other contracts currently within Beton Construction's portfolio. The Company continues to carry out major projects both in Turkey and abroad (Kaya and Kahraman, 2010). The index $\tilde{C}_{p p}$ is used to determine the best supplier for Beton Construction which plans to buy some steel to mix with daub to build stronger constructions. Beton Construction and experts determine that the diameter of the steel should be approximately between $8-10 \mathrm{~mm}$ to obtain the best results. The firm has three possible alternative suppliers. For this aim the followings are obtained as shown in Table 2.

Table 2 The process mean and variances for the diameter of steel (mm.)

\begin{tabular}{lccc}
\hline Supplier & Sample Size & $\bar{x}$ & $s$ \\
\hline Supplier-A & 200 & 9.10 & 0.24 \\
Supplier-B & 200 & 9.18 & 0.22 \\
Supplier-C & 200 & 9.08 & 0.23
\end{tabular}

The fuzzy process mean and variance are calculated with respect to Table 2 by using Eqs. (15-18). The membership functions of process mean and variance of diameter of steel (mm.) for Supplier-A are illustrated in Figures 1 and 2, respectively. The fuzzy estimations of process mean and variance for Supplier-A include not only all possible values with related membership value but also the crisp values $\bar{x}=9.10$ and $s^{2}=0.058$ with a membership value of 1.00 as seen in Figures 1 and 2, respectively. 


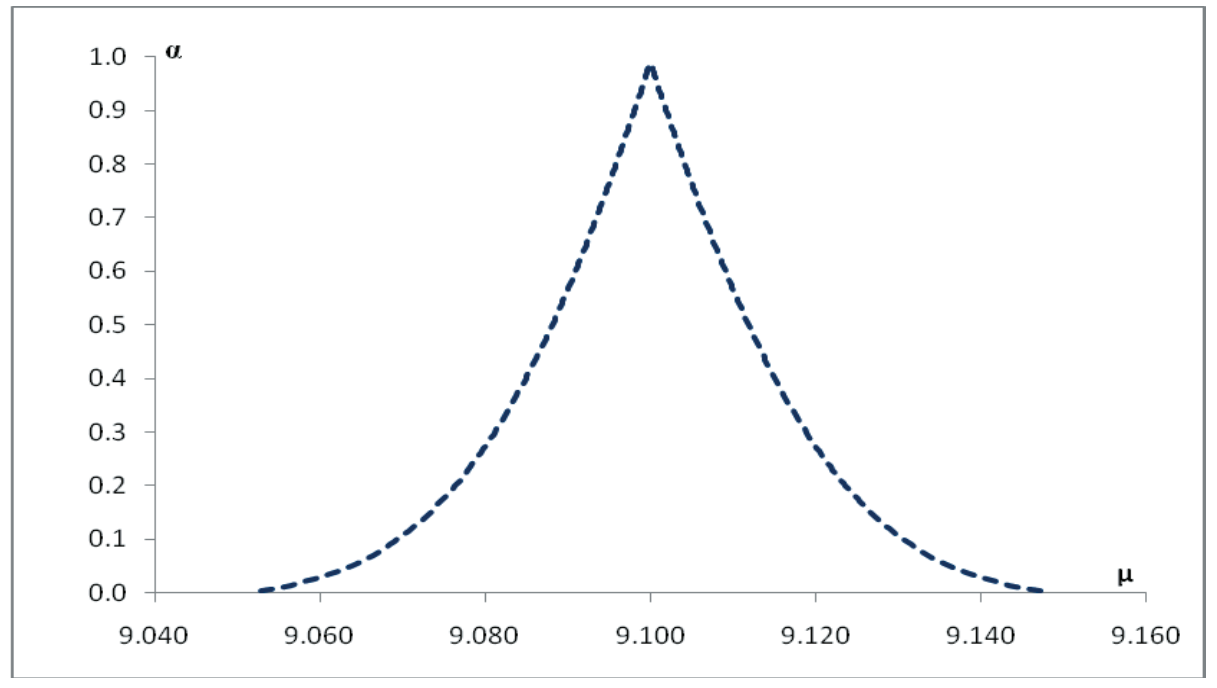

Figure 1 Membership function of process mean for Supplier-A

The fuzzy values for process mean and variance bring advantages to analyze the supplier alternatives more deeply and more flexible. Nevertheless, they can be more suitable to calculate fuzzy process capability indices.

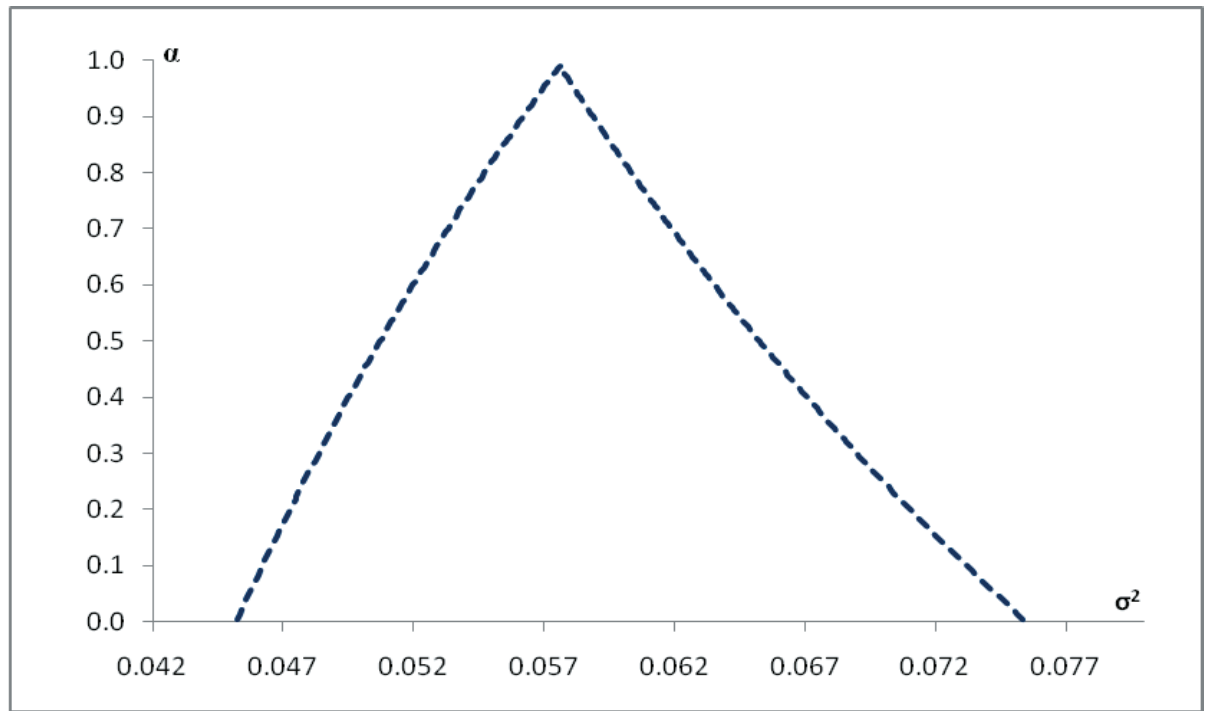

Figure 2 Membership function of process variance for Supplier-A

The fuzzy process mean and variance values are calculated for all of the supplier alternatives and they are shown in Table 3. These values will be used to obtain the indices $\tilde{C}_{i a}, \tilde{C}_{i p}$ and $\tilde{C}_{p p}$. 
Table 3 The fuzzy values for supplier alternatives

\begin{tabular}{cccc}
\hline & Supplier-A & Supplier-B & Supplier-C \\
\hline$\tilde{\mu}$ & $(9.050,9.100,9.150)$ & $(9.134,9.180,9.226)$ & $(9.032,9.080,9.128)$ \\
$\tilde{\sigma}^{2}$ & $(0.045,0.058,0.076)$ & $(0.038,0.048,0.063)$ & $(0.042,0.053,0.069)$ \\
\hline
\end{tabular}

When the most appropriate supplier for steel is determined, the SLs and $\mathrm{T}$ is defined by using linguistic variable "Approximately". The SLs and target values for three suppliers are defined as follows:

$\mathrm{US \tilde {L }}=$ Approximately $10.00=\mathrm{TFN}(9.95,10.00$, 10.05),

$\mathrm{LS} \mathrm{L}=$ Approximately $8.00=\mathrm{TFN}(7.95,8.00,8.05)$, $\tilde{\mathrm{T}}=$ Approximately $9.00=\mathrm{TFN}(8.95,9.00,9.05)$.

The indices $\tilde{C}_{i a}, \tilde{C}_{i p}$ and $\tilde{C}_{p p}$ are evaluated by using Eqs. (21-27) for TFN that are more suitable for this type of linguistic definition. The indices
$\tilde{C}_{i a}$ and $\tilde{C}_{i p}$ for Supplier-A are calculated as $(0.00$, $0.09,0.44)$ and $(0.34,0.52,0.84)$, respectively. Then the index $\tilde{C}_{p p}$ for Supplier-A whose membership function is shown in Figure 3 is calculated as $(0.34,0.61,1.28)$. As it can be seen from Figure 3 , the index $\tilde{C}_{p p}$ 's value has a possibility to take between 0.34 and 1.28 with different membership degrees.

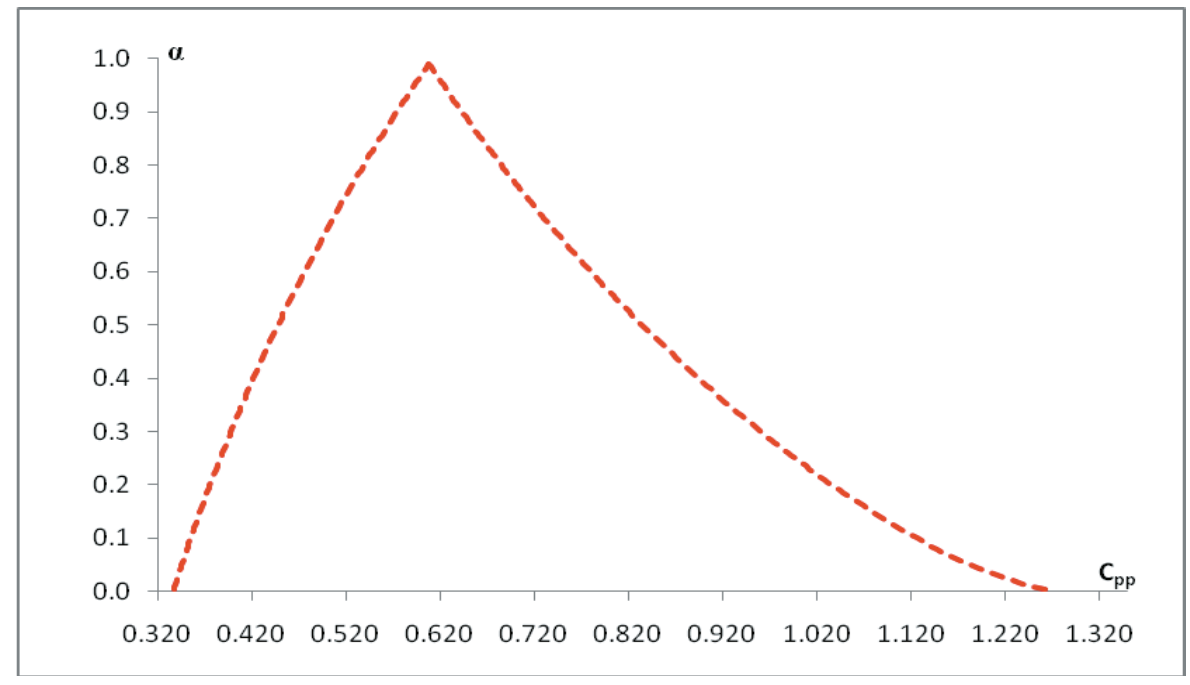

Figure 3 Membership function the index $\tilde{C}_{p p}$ for Supplier-A

As it seen from Figure 3, the Supplier-A's quality condition has a possibility to classify as "inadequate", "capable", "satisfactory" or "excellent". According to the total integral value method, the defuzzication value of the index $\tilde{C}_{p p}$ for Supplier-A is 0.71 that indicates that Supplier-A's quality condition is "capable".

The indices $\tilde{C}_{i a}$ and $\tilde{C}_{i p}$ for Supplier-C are also calculated as $(0.00,0.06,0.35)$ and $(0.31,0.48$, 0.77), respectively. Then index $\tilde{C}_{p p}$ for Supplier-C is calculated as $(0.31,0.53,1.12)$. The membership function of index $\tilde{C}_{p p}$ is shown in Figure 4 . As it seen from Figure 4 , the index $\tilde{C}_{p p}$ takes into account all possible values together with related degree of membership. This gives an advantage by obtaining more detailed and flexible analysis both to increase process quality and to decrease process variation. The index $\tilde{C}_{p p}$ has a possibility to take between 0.31 and 1.12 with different membership degrees. 


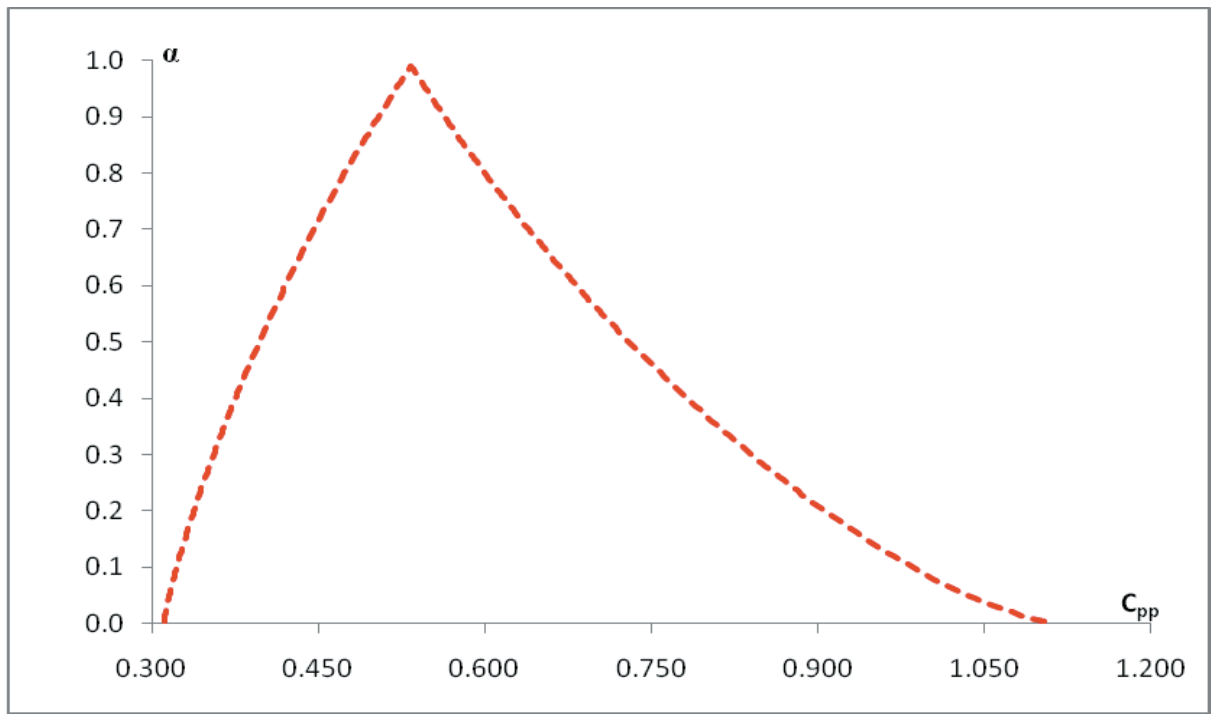

Figure 4 Membership function of the index $\tilde{C}_{p p}$ for for Supplier-C

As it seen from Figure 4, the quality condition of Supplier-C has a possibility to classify as from "inadequate" to "excellent". The defuzzication value of the index $\tilde{C}_{p p}$ for Supplier-C is determined as 0.62 that indicates that quality condition of Supplier-C is "capable" by using total integral value method.

Although the quality conditions for Suppliers A and $\mathrm{C}$ seem similar, the Supplier $\mathrm{C}$ is preferable since its index $\tilde{C}_{p p}$ indicates that its quality condition is closer to the condition "satisfactory" and is further the condition "inadequate" than Supplier-A. The same evaluation procedure is managed by taking into account Supplier-B whose fuzzy values are shown in Table 4. As a result, Supplier B is determined as the worst alternative.

Table 4 The fuzzy indices for supplier alternatives

\begin{tabular}{cccc}
\hline & Supplier-A & Supplier-B & Supplier-C \\
\hline$\tilde{C}_{i a}$ & $(0.00,0.09,0.44)$ & $(0.05,0.29,0.84)$ & $(0.00,0.06,0.35)$ \\
$\tilde{C}_{i p}$ & $(0.34,0.52,0.84)$ & $(0.28,0.44,0.70)$ & $(0.31,0.48,0.77)$ \\
$\tilde{C}_{p p}$ & $(0.34,0.61,1.28)$ & $(0.33,0.73,1.54)$ & $(0.31,0.53,1.12)$ \\
\hline
\end{tabular}

According to Table 4, Supplier-C is determined as the best alternative to buy building materials and the order of supplier alternative is determined as follows: $\{\mathrm{C}-\mathrm{A}-\mathrm{B}\}$.

In some cases, SLs or $\mathrm{T}$ can be defined by an expression like "between $\mathrm{X}$ and $\mathrm{Y}$ " where TrFN are more suitable to convert them to fuzzy numbers. In our supplier selection process they can be defined and are converted as follow:
$\mathrm{USL}=$ Between 9.95 and 10.00. Then, $\mathrm{US} \mathrm{L}=\mathrm{TrFN}$ $(9.90,9.95,10.00,10.05)$,

$\mathrm{LSL}=$ Between 7.95 and 8.00. Then, $\mathrm{LS} \mathrm{L}=\mathrm{TrFN}$ $(7.85,7.95,8.00,8.05)$,

$\tilde{\mathrm{T}}=$ Between 8.95 and 9.00. Then, $\mathrm{L} \tilde{\mathrm{S}} \mathrm{L}=\mathrm{TrFN}$ $(8.90,8.95,9.00,9.05)$.

The index $\tilde{C}_{p p}$ of Supplier-C for TrFN case is calculated as $(0.29,0.48,0.70,1.60)$ and its 
membership function is shown in Figure 5. The index $\tilde{C}_{p p}$ 's value has a possibility to take between from 0.29 to 1.60 with different membership degrees.

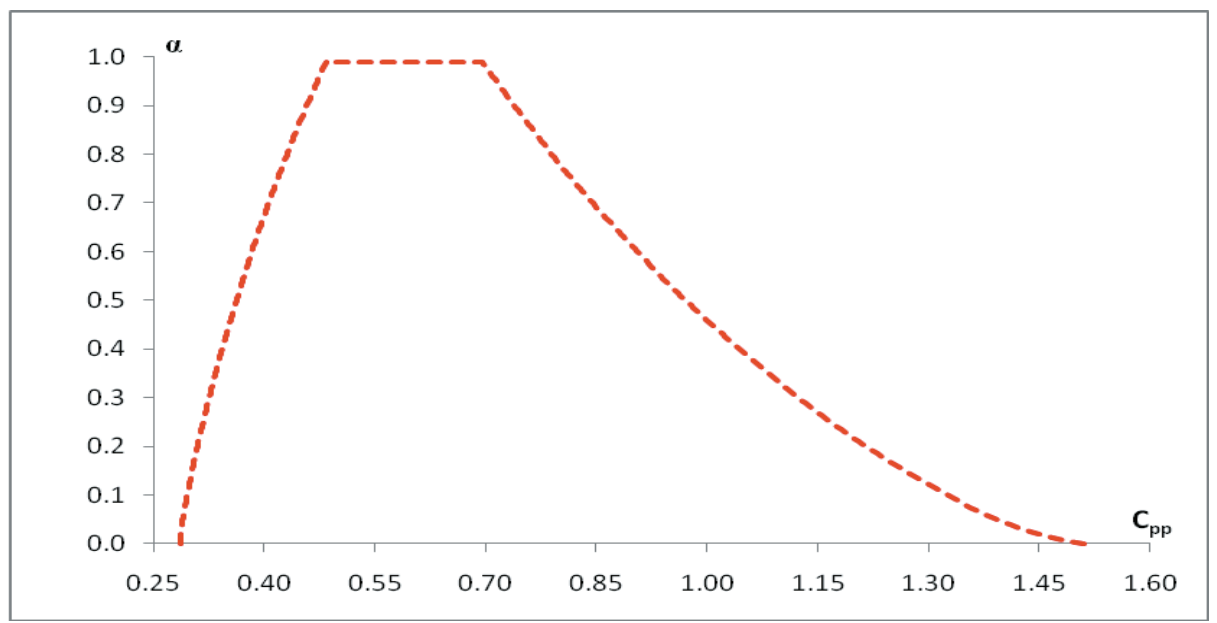

Figure 5 Membership function of the index $\tilde{C}_{p p}$ for Supplier-C

The indices $\tilde{C}_{i a}, \tilde{C}_{i p}$ and $\tilde{C}_{p p}$ for supplier alternatives are also calculated as shown in Table 5.

Table 5 The fuzzy indices for supplier alternatives

\begin{tabular}{lccc}
\hline & Supplier-A & Supplier-B & Supplier-C \\
\hline$\tilde{C}_{i a}$ & $(0.00,0.08,0.22,0.87)$ & $(0.04,0.26,0.53,1.43)$ & $(0.01,0.05,0.17,0.73)$ \\
$\tilde{C}_{i p}$ & $(0.31,0.47,0.57,0.95)$ & $(0.26,0.40,0.48,0.80)$ & $(0.28,0.43,0.53,0.87)$ \\
$\tilde{C}_{p p}$ & $(0.31,0.55,0.79,1.82)$ & $(0.30,0.66,1.01,2.23)$ & $(0.29,0.48,0.70,1.60)$ \\
\hline
\end{tabular}

According to Table 5, Supplier-C is also determined as the best alternative to buy building materials since its index $\tilde{C}_{p p}$ indicates that its quality condition is closer to the condition "satisfactory" and is further the condition "inadequate" than Suppliers A and B. The supplier $\mathrm{A}$ is also determined as more suitable than Supplier $\mathrm{B}$. As a result, the order of supplier alternative is determined as follows: $\{\mathrm{C}-\mathrm{A}-\mathrm{B}\}$.

\section{Conclusion}

The capability analysis of a process that is a very effective tool to summarize process performance by producing statistical values called process capability indices is a necessity in order to improve process. The process capability analysis can be also defined as a measure of inherent variability in a process as compared to the requirements of the product which defined by using SLs. Although process capability analysis generally used in manufacturing process, in this paper they are suggested for a decision making process. In the literature, there are many successful techniques those have been proposed for decision making processes. In this paper a new decision making tool based on process incapability index has been suggested and is successfully applied. This new decision making tool evaluate decision making process quickly and easily.

In this paper, one of the most important process capability indices, the index $C_{p p}$ which is easy to apply, and provides more process information than other process PCIs is analyzed together with indices $C_{i a}$ and $C_{i p}$.

The FST that has been studied extensively over the past 30 years can be used to overcome the main 
difficulty of PCIs, crisp definition. The FST brings an advantage by a flexible definition and more detailed evaluation on process capability analysis. So the index $C_{p p}$ is analyzed under fuzzy environment and the index $\tilde{C}_{p p}$ is obtained. By the way the fuzzy estimations of process mean and variance are produced and then fuzzy estimations of the index $\tilde{C}_{i a}$ and the index $\tilde{C}_{i p}$ are obtained.

The proposed fuzzy indices are used in a decision making process to determine the most appropriate supplier for a construction firm and to rank of the suppliers have been determined by using these indices very successfully. It is understood that fuzzy indices include more information about supplier performance and supplier's quality condition. However, only quality is considered for this problem by taking into account the index $\tilde{C}_{p p}$. Since we have an assumption that the suppliers are equivalent in terms of other criteria other than quality (i.e. price, delivery performance etc.).

In the future research, the obtained results by fuzzy process capability analysis can be extended for multicriteria decision making (MCDM) processes and the results can be confirmed by other techniques used in MCDM such as analytic hierarchy process, analytic network process, and TOPSIS.

\section{References}

1. Abdolshah, M., Yusuff, R.M., Hong, T.S., Ismail, M.Y.B, Sadigha, A.N. (2010). Measuring process capability index $\mathrm{C}_{\mathrm{pmk}}$ with fuzzy data and compare it with other fuzzy process capability indices. Expert Systems with Applications, doi:10.1016/j.eswa.2010.11.101.

2. Buckley, J.J. (2004). Fuzzy statistics, SpringerVerlag, Berlin Heidelberg.

3. Buckley, J.J. (2005). Simulating fuzzy systems, Springer-Verlag, Berlin Heidelberg.

4. Buckley, J.J. (2006). Fuzzy probability and statistics, Springer-Verlag, Berlin Heidelberg.

5. Buckley, J.J., Eslami, E. (2004). Uncertain probabilities II: The continuous case, Soft Computing. 8, 193-199.

6. Chen, C. C., Lai, C. M., Nien, H. Y. (2010). Measuring process capability index $\mathrm{C}_{\mathrm{pm}}$ with fuzzy data. Quality and Quantity. 44, 529-535.
7. Chen, K.S. (1998a) Estimation of the process incapability index. Communications in Statistics Theory Methods, 27(4):1263-1274

8. Chen, K.S., Chen, T.W. (2008). Multi-process capability plot and fuzzy inference evaluation. International Journal of Production Economics, 111(1), 70-79.

9. Chen, K.S.,'Chen, K.L., Li, R.K. (2005). Contract manufacturer selection by using the process incapability index $\mathrm{C}_{\mathrm{pp}}$. International Journal of Advanced Manufacturing Technology, 26, 686-692.

10. Chen, T. W., Chen, K. S., Lin, J. Y. (2003a). Fuzzy evaluation of process capability for bigger-the-best type products. International Journal of Advanced Manufacturing Technology, 21, 820-826.

11. Chen, T.W., Lin, J.Y., Chen, K.S. (2003b). Selecting a supplier by fuzzy evaluation of capability indices $\mathrm{C}_{\mathrm{pm}}$, International Journal of Advanced Manufacturing Technology, 22, 534540.

12. Chou, C.Y., Lin, Y.C., Chang, C.L., Chen, C.H. (2006). On the bootstrap confidence intervals of the process incapability index $\mathrm{C}_{\mathrm{pp}}$. Reliability Engineering and System Safety, 91, 452-459.

13. Gao, Y., Huang, M. (2003). Optimal process tolerance balancing based on process capabilities. International Journal of Advanced Manufacturing Technology, 21, 501-507.

14. Greenwich, M, Jahr-Schaffrath, B.L., (1995). A process incapability index. International Journal of Quality \& Reliability Management, 12(4), 58-71.

15. Hsu, B.M., Shu, M.H. (2008) Fuzzy inference to assess manufacturing process capability with imprecise data. European Journal of Operational Research, 186(2), 652-670.

16. Huang, M.L., Chen, K.S., Li, R.K. (2002). Process capability evaluation for a PVC pipe product family. The Asian Journal on Quality, 3, 61-70.

17. Kahraman, C., Beskese, A., Ruan, D. (2004). Measuring flexibility of computer integrated manufacturing systems using fuzzy cash flow analysis. Information Sciences, 168, 77-94.

18. Kahraman, C., Gülbay, M., Kabak, Ö. (2006). Applications of fuzzy sets in industrial engineering: A topical classification, Studies in Fuzziness and Soft Computing, 201, 1-55. 
19. Kahraman, C., Kaya, İ. (2009). Fuzzy process capability indices for quality control of irrigation water. Stochastic Environmental Research and Risk Assessment, 23(4), 451-462.

20. Kahraman, C., Kaya, İ. (2009b). Fuzzy process accuracy index to evaluate risk assessment of drought effects in Turkey, Human and Ecological Risk Assessment: An International Journal, 15(4), 789-810.

21. Kahraman, C., Kaya, İ. (2011). Fuzzy estimations of process incapability index. Proceedings of the World Congress on Engineering, pp: 1106-1110.

22. Kane, V.E. (1986). Process capability indices. Journal of Quality Technology, 18(1), 41-52.

23. Kaya, İ., Baraçl1, H. (2012). Fuzzy process incapability index with asymmetric tolerances, Journal of Multiple Valued Logic and Soft Computing, 18 (5-6), 493-511.

24. Kaya, İ., Kahraman, C. (2008). Fuzzy process capability analyses: An application to teaching processes. Journal of Intelligent \& Fuzzy Systems, 19(4-5), 259-272.

25. Kaya, İ., Kahraman, C. (2009). Fuzzy robust process capability indices for risk assessment of air pollution. Stochastic Environmental Research and Risk Assessment, 23(4), 529-541.

26. Kaya, İ., Kahraman, C. (2009b). Air pollution control using fuzzy process capability indices in six-sigma approach. Human and Ecological Risk Assessment: An International Journal, 15(4), 689-713.

27. Kaya, İ., Kahraman, C. (2010). Development of fuzzy process accuracy index for decision making problems, Information Sciences, 180(6), 861-872.

28. Kaya, İ., Kahraman, C. (2010b). A new perspective on fuzzy process capability indices: robustness, Expert Systems with Applications, 37(6), 4593-4600.

29. Kaya, İ., Kahraman, C. (2010c). Fuzzy process capability analyses with fuzzy normal distribution, Expert Systems with Applications, 37(7), 5390-5403.

30. Kaya, İ., Kahraman, C. (2011). Process capability analyses with fuzzy parameters, Expert Systems with Applications, 38(9), 1191811927.

31. Kaya, İ., Kahraman, C. (2011a). Fuzzy process capability indices with asymmetric tolerances, Expert Systems with Applications, 38(12). 14882-14890.

32. Kaya, İ., Kahraman, C. (2011b). Process capability analyses based on fuzzy measurements and fuzzy control charts, Expert Systems with Applications, 38(4), 3172-3184.

33. Ke, J.C., Chu, Y.K., Chung, Y.T., Lin, P.C. (2009). Assessing non-normally distributed processes by interval estimation of the incapability index $\mathrm{C}_{\mathrm{pp}}$. Quality and Reliability Engineering International, 25, 427-437.

34. Kotz, S., Johnson, N.L., (1993). Process Capability Indices. Chapman \& Hall, London, UK.

35. Lee, H.T. (2001). $\mathrm{C}_{\mathrm{pk}}$ index estimation using fuzzy numbers. European Journal of Operational Research, 129, 683-688.

36. Lee, Y.H., Wei, C.C., Chang, C.L. (1999). Fuzzy design of process tolerances to maximise process capability. International Journal of Advanced Manufacturing Technology, 15, 655659 ,

37. Liou, T.S., Wang, M. J. (1992). Ranking fuzzy numbers with integral value. Fuzzy Sets and Systems, 50, 247-255.

38. Parchami, A., Mashinchi, M. (2007). Fuzzy estimation for process capability indices. Information Sciences, 177, 1452-1462.

39. Parchami, A., Mashinchi, M. (2010). A new generation of process capability indices, Journal of Applied Statistics, 37(1), 77-89.

40. Parchami, A., Mashinchi, M., Maleki, H.R. (2006). Fuzzy confidence interval for fuzzy process capability index. Journal of Intelligent \& Fuzzy Systems, 17, 287-295.

41. Parchami, A., Mashinchi, M., Yavari, A.R., Maleki, H.R. (2005). Process Capability Indices as Fuzzy Numbers. Austrian Journal of Statistics, 34(4), 391-402.

42. Pearn W.L., Chen, K.L., Chen, K.S. (2002). A practical implementation of the incapability index $\mathrm{C}_{\mathrm{pp}}$. International Journal of Industrial Engineering, 9(4):372-383.

43. Ramezani, Z., Parchami, A., Mashinchi, M. (2009). Fuzzy confidence regions for the Taguchi capability index, International Journal of Systems Science, doi: $10.1080 / 00207720903267890$

44. Tsai, C. C., Chen, C. C. (2006). Making decision to evaluate process capability index $C_{p}$ with fuzzy numbers. International Journal of Advanced Manufacturing Technology, 30, 334339.

45. Wu, C.W. (2009). Decision-making in testing process performance with fuzzy data. European Journal of Operational Research, 193(2), 499509. 
46. Wu, C.W., Pearn W.L., Kotz, S., (2009). An overview of theory and practice on process capability indices for quality assurance. International Journal of Production Economics, 117(2), 338-359.

47. Yongting, C. (1996). Fuzzy quality and analysis on fuzzy probability. Fuzzy Sets Systems, 83, 283-290.

48. Zadeh, L. A. (1965). Fuzzy sets. Information and Control, 8, 338-359. 